\title{
Epidemiology of chronic pain in the office of a pain specialist neurologist
}

\author{
Epidemiologia da dor crônica no consultório de um neurologista especialista em dor \\ Karen dos Santos Ferreira, José Geraldo Speciali
}

\begin{abstract}
Objective: The objective of the present report was to describe the working experience of a pain specialist neurologist after concluding a medical residency program on neurology, area of concentration pain. Method: A retrospective study was conducted for one year in the office of a pain specialist neurologist. Patients older than 18 years with chronic pain according to the criteria of the International Association for the Study of Pain, were included. Demographic data, chronic pain data and the treatments instituted were investigated. Results: A total of 241 medical records were reviewed, mean patient age was 52.4 years and 79 (66.9\%) were women, and the mean score on a numeric pain scale was 8.69. The diagnoses were headaches (74.6\%), neuropathic pain (17\%) and ostheomuscular pain (8.2\%). We did not detect cancer pain. Patients received medication and procedures of anesthetic blockade. Conclusion: This data can guide new medical residency programs on Neurology, area of concentration pain, to plan activities and studies.
\end{abstract}

Keywords: chronic pain, neurology, medical residency.

\section{RESUMO}

Objetivo: O objetivo do presente estudo foi descrever a experiência de trabalho de um neurologista especialista em dor, após concluir um programa de residência médica em neurologia, área de concentração: dor. Método: Um estudo retrospectivo foi realizado por 1 ano no consultório de um neurologista especialista em dor. Pacientes com mais de 18 anos, com dor crônica de acordo com os critérios da Associação Internacional para o Estudo da Dor, foram incluídos. Dados demográficos, da dor crônica e tratamentos instituídos foram investigados. Resultados: Um total de 241 prontuários médicos foram revisados, a média de idade dos pacientes foi de 52,4 anos, 79 (66,9\%) eram mulheres, e o escore médio em uma escala numérica de dor foi de 8,69. Os diagnósticos foram cefaleias (74,6\%), dores neuropáticas (17\%) e dores osteomusculares (8,2\%). Não detectamos dor do câncer. Os pacientes receberam medicações e procedimentos de bloqueios anestésicos. Conclusão: Estes dados podem orientar novos programas de residência médica em neurologia, sub-área da Dor, para planejar as atividades e estudos.

Palavras-chave: dor crônica, neurologia, residência médica.

The world prevalence of chronic pain is approximately $40 \%$, generating enormous financial and social damage $\mathrm{e}^{1,2,3,4,5}$. There still is a severe shortage of professionals working in this area. Thus, over the last few years, the training of health professionals in the pain area has been gaining space in Brazil ${ }^{1}$. Among the new specialties acting in this area, Neurology was approved by the Brazilian Federal Council of Medicine in 2002 (resolution no. 1634) as an area of activity in pain ${ }^{6}$. Over the last few years, the medical residency program for Neurologists working with Pain has been implemented at some institutions, resulting in the first group of neurologists completing this program with this type of training. The objectives of qualifying neurologists for work in the Pain area were based on their theoretical knowledge of the mechanisms of chronic pain, headaches, neuropathic pain, low back pain, rheumatological pain, palliative care, as well as their work with invasive procedures (peripheral nerve blockade) and anesthesiology procedures of medium complexity. Since then, some questions have arisen: what kind of working experience have these neurologists had? Who are the patients who effectively look for a neurologist for treatment and how are they approached?

Within this context, in an attempt to answer these questions, the objective of the present study was to describe the one-year prevalence of chronic pain in the office of a Pain Specialist Neurologist who concluded a medical residency program at the University Hospital, Faculty of Medicine at Ribeirão Preto, University of São Paulo (FMRP-USP).

Universidade de São Paulo, Faculdade de Medicina de Ribeirão Preto, Divisão de Neurologia, Departamento de Neurociências e Ciências do Comportamento, Sao Paulo SP, Brazil.

Correspondence: Karen dos Santos Ferreira; Avenida Bandeirantes, 3900; 14048-900 Ribeirão Preto SP, Brasil; E-mail: karenferreira@usp.br

Conflict of interest: There is no conflict of interest to declare.

Received 10 May 2014; Received in final form 16 January 2015; Accepted 05 February 2015. 


\section{METHOD}

The study was conducted in the office of a Pain Specialist Neurologist who had concluded a medical residency program at the University Hospital, Faculty of Medicine at Ribeirão Preto, University of São Paulo, in 2008. This is an outpatient clinic, that attends a specific population from health insurance companies or private patients. All the records of visits held in 2012, involving patients older than 18 years with chronic pain according to the criteria of the International Association for the Study of Pain (IASP) ${ }^{7}$, were reviewed. Demographic data (age, gender), the characteristics of chronic pain (location, intensity, diagnoses) and the treatments instituted (medication, nerve blocks) were investigated.

The Ethics Committee of School of Medicine of Ribeirão Preto, University of São Paulo, approved the study (CAAE: 22649914.4.0000.5440).

Data were processed in the Department of Statistics of FMRP-USP using the SPSS software.

\section{RESULTS}

The medical records of 241 patient with chronic pain were reviewed. Of the patients evaluated, $79(66.9 \%)$ were women and 39 (33.1\%) were men; mean patient age was 52.4 years (Table 1 ).

On the occasion of the first visit, the mean score of the numeric pain rating scale was 8.69. The most frequent type of pain was headache. The diagnoses were divided into 3 major groups: 180 patients (74.6\%) had headaches, 41 (17\%) had neuropathic pain, and $20(8.2 \%)$ had ostheomuscular pain. No patient had oncologic pain. The sub-diagnoses are described in Table 2 . The medications most frequently used for treatment were tricyclic

Table 1. Chronic pain patients treated in 2012 (n: 241).

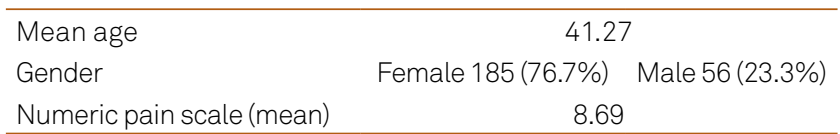

antidepressants $(78,32.3 \%)$, followed by topiramate $(53,21.9 \%)$ and pregabalin $(29,12 \%)$ (Table 3). Opioids were used by 15 patients (6.2\%). Sixty-four patients (26.5\%) received procedures of anesthetic blockade, the most frequent being blockade of the occipital nerves (16, 6.6\%), followed by facet $(6,24 \%)$, epidural (5, $2.0 \%$ ) and intercostal $(5,2.0 \%)$ blockade (Table 4$)$.

\section{DISCUSSION}

In 1997, the Executive Council of the American Academy of Neurology (AAN) approved an initiative for the promotion of the participation of neurologists in the diagnosis and treatment of pain. In the United States of America (USA), the assessment and management of pain and patient education are criteria for good hospital care. The AAN encourages neurologists to participate in an increasing and effective manner in the assessment and treatment of pain, which require learning about this topic. The training opportunities for professionals dealing with pain include learning during the medical residency, one-year fellowships from the American Board of Psychiatry and Neurology, and a growing evidence-based literature. Other specialties also deal with chronic pain in the USA, such as anesthesiology, psychiatry, physical medicine and rehabilitation, with the professionals acquiring qualification by entering one-year fellowship programs supported by the American Board of Anesthesiology. These fellowships are based on a multidisciplinary program involving several areas, and provide experience in interventional procedures, rehabilitation, oncologic pain, palliative care, pediatric pain, neurologic pain, and clinical research ${ }^{8}$.

In Western European countries, candidates from different specialties are selected for fellowships for the Treatment of Pain at Excellence Centers in various countries, sponsored by the European Federation of IASP Chapters 9 .

In Brazil, a medical residency program for neurologists dealing with Pain has been implemented at several institutions over the last few years, with very preliminary results having been obtained regarding the first neurologists who have received this training.

Table 2. Pain diagnoses in chronic pain patients treated in 2012 ( $\mathrm{n}: 241)$.

\begin{tabular}{|c|c|c|c|c|c|}
\hline Headache & $\mathrm{n}(\%)$ & Neuropathic pain & $\mathrm{n}(\%)$ & Ostheomuscular pain & $\mathrm{n}(\%)$ \\
\hline Migraine without aura & $104(43.1 \%)$ & Post-herpetic & $8(3.3 \%)$ & Fibromyalgia & $8(3.3 \%)$ \\
\hline Migraine with aura & $18(7.4 \%)$ & Radiculopathy & $6(2.4 \%)$ & Myofascial pain & $5(2.0 \%)$ \\
\hline Cervicogenic headache & $15(6.2 \%)$ & Trigeminal Neuralgia & $6(2.4 \%)$ & Repetitive strain injury & $2(0.8 \%)$ \\
\hline Tensional headache & $11(4.5 \%)$ & Lumbar stenosis & $5(2.0 \%)$ & Shoulder pain & $2(0.8 \%)$ \\
\hline Post-traumatic headache & $9(3.7 \%)$ & Small Fiber Polineuropathy & $4(1.6 \%)$ & Parkinson disease & $1(0.4 \%)$ \\
\hline Cluster headache & $4(1.6 \%)$ & Post-laminectomy syndrome & $3(1.2 \%)$ & Mechanical lumbar pain & $1(0.4 \%)$ \\
\hline Idiopathic intracranial hypertension & $4(1.6 \%)$ & Diabetic neuropathy & $3(1.2 \%)$ & Bursitis & $1(0.4 \%)$ \\
\hline Nummular headache & $2(0.8 \%)$ & Neuropathic facial pain & $3(1.2 \%)$ & & \\
\hline Other trigeminal autonomic cephalalgias & $2(0.8 \%)$ & Medular trauma & $1(0.4 \%)$ & & \\
\hline Primary thunderclap headache & $2(0.8 \%)$ & Complex Pain Syndrome & $1(0.4 \%)$ & & \\
\hline Stabbing headache & $2(0.8 \%)$ & Central pain Post-stroke & $1(0.4 \%)$ & & \\
\hline Others & $7(2.9 \%)$ & & & & \\
\hline Total & $180(74.7 \%)$ & & $41(17.0 \%)$ & & $20(8.3 \%)$ \\
\hline
\end{tabular}


Table 3. Medications most frequently used by chronic pain patients treated in 2012

\begin{tabular}{lc}
\hline \multicolumn{1}{c}{ Medication } & $\mathrm{n}(\%)$ \\
\hline Tricyclic antidepressants & $78(32.3 \%)$ \\
Topiramate & $53(21.9 \%)$ \\
Pregabalin & $29(12.0 \%)$ \\
Dual antidepressants & $18(7.4 \%)$ \\
Valproate & $13(5.3 \%)$ \\
Clorpromazine & $10(4.1 \%)$ \\
Gabapentine & $8(3.3 \%)$ \\
Propranolol & $8(3.3 \%)$ \\
Flunarizine & $8(3.3 \%)$ \\
Verapamil & $4(1.6 \%)$ \\
Indometacine & $4(1.6 \%)$ \\
Opioids & $15(6.2 \%)$ \\
Capsaicine & $1(0.4 \%)$ \\
\hline
\end{tabular}

Regarding the patients with chronic pain who seek these neurologists, the epidemiological demographic data obtained in the present study are similar to literature data obtained in previous studies about patients with chronic pain, aged on average 45 to 65 years and more frequent in women.

Gureje et al., published the first large-scale cross-national study of persistent pain among primary care patients, conducted by the World Health Organization (WHO), estimating its prevalence and impacts in a wide range of countries. Across all centers (including two centers in South America, Rio de Janeiro and Santiago), 22\% of primary care patients reported persistent pain ( $25 \%$ of women and $16 \%$ of men). Lumbar pain were found in $47.8 \%$ of 5468 patients interviewed, headache in $45 \%$, joint pain in $41 \%$, and limb pain in $34.3 \%^{5}$.

The prevalence of chronic pain defined for the general population, by a multicenter research conducted in 17 countries, is about $37 \%$ in developed countries and $41 \%$ in developing countries. They detected lumbar pain in $40 \%$ of 42249 patients interviewed and headache in $14.4 \%^{10}$.

In general, lumbar pain is the most prevalence pain site in the world. In a population study, Elliott et al. detected 1817 patients with chronic pain, 576 of whom reported lumbar pain as the main cause of pain ${ }^{3}$.

The literature about chronic pain is scarce in developing countries, and there is a lack of studies conducted at Pain Clinics. In South Africa, using face-to-face interviews, Walker reported a $42.9 \%$ prevalence of chronic pain, with lumbar pain in $49.2 \%$ of this people ${ }^{11}$. In Brazil, Jacobsen interviewed 485 patients in a Pain Unit at the University of Sao Paulo, and reported that the most prevalent diagnosis was fibromyalgia $(21.9 \%)^{12}$. Ferreira et al., described patients with chronic pain treated at the Pain Unit of the Central Hospital of Maputo, Mozambique. Of 118 patients interviewed, 79 (66.9\%) were women and mean patient age was 52.4 years. Lumbar pain was the most frequent site of pain $(36.4 \%)^{13}$.

In the present study, headache was the main site of pain, whereas most world studies have detected low back pain as
Table 4. Procedures received by chronic pain patients treated in 2012

\begin{tabular}{lc}
\hline \multicolumn{1}{c}{ Procedure } & $\mathrm{n}(\%)$ \\
\hline Anesthetic blockade & \\
Occipital nerve block & $16(6.6 \%)$ \\
Facet joint block & $6(2.4 \%)$ \\
Epidural block & $5(2.0 \%)$ \\
Intercostal nerve block & $5(2.0 \%)$ \\
Suprascapular nerve block & $5(2.0 \%)$ \\
Surgical scars & $3(1.2 \%)$ \\
Gasser ganglia block & $2(0.8 \%)$ \\
Supratrochlear nerve block & $2(0.8 \%)$ \\
Maxillary e mandibular & $2(0.8 \%)$ \\
Numular points & $2(0.8 \%)$ \\
Auriculotemporal nerve block & $2(0.8 \%)$ \\
Sympathetic ganglia & $1(0.4 \%)$ \\
Supraorbital nerve block & $1(0.4 \%)$ \\
Others (femoral nerve, joint blocks) & $3(1.2 \%)$ \\
Myofascial & \\
Trigger point injection & $6(2.4 \%)$ \\
Radiofrequency & $3(1.2 \%)$ \\
Total & $64(100 \%)$ \\
\hline
\end{tabular}

the main pain topography. We believe that patients with other causes of chronic pain are not being referred yet to neurologists, since pain area of concentration on Neurology is recent. Patients with headache are believed to seek more frequently a neurologist rather than a specialist in another area. On the other hand, patients with low back pain usually move between various professionals such as orthopedists, neurosurgeons, anesthesiologists specializing in pain, or rheumatologists before solving their problem. Headache is the cause of suffering, disability and loss of quality of life and is one of the most important causes of chronic pain in the population. According to an article published in Lancet Neurology in 2008 , the prevalence of headache in the general adult population is $47 \%$, with $10 \%$ involving migraine, $38 \%$ tension headache, and $3 \%$ chronic headaches lasting more than 15 days $^{14}$. The social costs related to headache in general, including lost work days and treatment costs, are considerable ${ }^{15}$.

Neuropathic pain, as defined by the Neuropathic Pain Special Interest Group - IASP, corresponds to pain occurring as a direct consequence of injury or disease, affecting the neurosensory system ${ }^{16}$. Its world prevalence is about 3 to $8 \%$ of the population ${ }^{17,18}$. In the present study, the most frequent causes among patients with neuropathic pain were post-herpetic neuralgia and radiculopathy. Most published studies have reported the lower limbs as the most frequently affected site ${ }^{17}$. The care of patients with neuropathic pain is a differential item for neurologists who are pain specialists.

Ostheomuscular or musculoskeletal pain is a condition that includes a variety of disorders which cause pain in bones, joints, or surrounding structures. Musculoskeletal pain due to excessive use affects $33 \%$ of adults and is responsible for $29 \%$ of work absenteeism ${ }^{19}$. 
About 18 million people in the world suffer oncologic pain, which is usually incapacitating, being very intense in $30 \%$ of patients. It should be pointed out that cancer pain is still undertreated even in more socioculturally advanced countries due to poor information on the part of health professionals in the area of palliative care and pain relief and to resistance of the patients themselves due to cultural factors ${ }^{20}$. In the present study we did not detect cancer pain among our patients. We believe oncologic pain patients are being treated by their oncologists and they do not reach the neurologic clinic.

Regarding the treatments instituted, the medications most frequently used were amitriptyline, topiramate and pregabalin. The use of amitriptyline and topiramate was justified by the large number of patients with headache, with amitriptyline and pregabalin being the medications of choice for neuropathic pain ${ }^{21}$. The choice of the drugs was not influenced by socio-economic status of the patient, the price of the drug or the availability of the drug at the public health system. Opioids were seldom used, perhaps because of the absence of cancer pain in the present sample. A still controversial question is the use of opioids for non-oncologic chronic pain in disorders such as headache, neuropathy, post-laminectomy syndrome, fibromyalgia and other pain syndromes ${ }^{8}$. Invasive procedures (anesthetic blockade) were performed in 64 (26.5\%) patients. We should emphasize that neurologists who are qualified for the treatment of chronic pain must be prepared to provide specialized care and procedures.

Over the last few years, the presence of neurologists in the area of treatment of cronic pain has become a world trend. The programs of medical residency for neurologists working with pain encourage neurologists to participate in an increasing and effective manner in the evaluation and treatment of pain. The training opportunities for the professionals working with this treatment are an important step for the improvement of the effectiveness of the treatment instituted. Since this specialty is new, it would be desirable to be made public information campaigns to medical and lay people, so patients can be properly referral.

In conclusion, chronic pain is a serious health problem all over the world, generating physical disability and social, emotional an economic damage. A first step for a more effective approach to the problem is to know it prevalence and peculiarities. The present study shows that the training of neurologists working in the pain area should give priority to the following causes of pain: primary headaches, neuropathic pain and musculoskeletal pain, with emphasis on Fibromyalgia and Miofascial pain in these last area. Next, more professionals should be habilitated for providing care, establishing treatment strategies, and finally, the performance of these professionals should be evaluated. Only in this way will it be possible to improve the way we deal with such relevant problem.

\section{References}

1. Teixeira MJ. Dor: manual para o clínico. Rio de Janeiro: Atheneu; 2006.

2. Croft P, Blyth FM, Windt D, editors. Chronic pain epidemiology from aetiology to public health. Oxford: Oxford University Press; 2010.

3. Elliott AM, Smith BH, Penny KI, Smith WC, Chambers WA. The epidemiology of chronic pain in the community. Lancet. 1999;354(9186):1248-52.

4. Gaskin DJ, Richard P. The economic costs of pain in the United States.J Pain. 2012;13(8):715-24. http://dx.doi.org/10.1016/j.jpain.2012.03.009

5. Gureje O, Von Korff M, Smion GE, Gater R. Persistent pain and wellbeing: a World Health Organization study in primary care. JAMA. 1998;280(2):147-51. http://dx.doi.org/10.1001/jama.280.2.147

6. Conselho Federal de Medicina. Resolução CFM no 1634/2002. Dispõe sobre convênio de reconhecimento de especialidades médicas firmado entre o Conselho Federal de Medicina CFM, a Associação Médica Brasileira - AMB e a Comissão Nacional de Residência Médica - CNRM. Diário Oficial União. 29 abr 2002;seção1:81.

7. International Association for the Study of Pain - IASP. Classification of chronic pain. 2nd ed rev. Washingoton, DC: International Association for the Study of Pain; 2011 [cited 2001 July 10]. Available from: http://www. iasp-pain.org/PublicationsNews/Content.aspx?ltemNumber=1673

8. American Academy of Neurology Ethics, Law and Humanities Committee. Ethical considerations for neurologists in the management of chronic pain. Neurology. 2001;57(12):2166-7.

9. European Pain Federation - EFIC. EFIC chapters. Belgium: European Pain Federation; 2012 [cited 2014 Nov]. Available from: http://www.efic.org/index.asp?sub=3joJQ8061FVMeR

10. Tsang A, Von Korff M, Lee S, Alonso J, Karam E, Angemeyer $\mathrm{MC}$ et al. Common chronic pain conditions in developed and developing countries: gender and age differences and comorbidity with depression-anxiety disorders. J Pain. 2008;9(10):883-91. http://dx.doi.org/10.1016/j.jpain.2008.05.005

11. Walker SP, Odendaal CL, Esterhuyse KGF. Biographical, pain and psychosocial data for a South African sample of chronic pain patients. South Afr J Anaesth Analg. 2006;12(2):62-6. http://dx.doi.org/10.1080/22201173.2006.10872440

12. Teixeira MJ, Teixeira WGJ, Santos FPS, et al. Clinical epidemiology of musculoskeletal pain. Rev Med. 2001;80(1):1-21.

13. Ferreira KS, Schwalbach MT, Schwalbach J, SpecialiJG. A pain unit in a developing country: epidemiology of chronic pain in Maputo, Mozambique. Pain Med. 2014;15(11):1986-8. http://dx.doi.org/10.1111/pme.12544

14. Jensen R, Stovner LJ. Epidemiology and comorbidity of headache. Lancet Neurol. 2008;7(4):354-61. http://dx.doi.org/10.1016/\$1474-4422(08)70062-0

15. Bigal ME, Lipton RB, Stewart WF. The epidemiology and impact of migraine. Curr Neurol Neurosci Rep. 2004;4(2):98-104. http://dx.doi.org/10.1007/s11910-004-0022-8

16. Haanpää M, Attal N, Backonja M, Baron R, Bennett M, Bouhassira $D$ et al. NeuPSIG guidelines on neuropathic pain assessment. Pain. 2011;152(1):14-27. http://dx.doi.org/10.1016/j.pain.2010.07.031

17. Bouhassira D, Lantéri-Minet M, Attal N, Laurent B, Touboul C. Prevalence of chronic pain with neuropathic characteristics in the general population. Pain. 2008;136(3):380-7. http://dx.doi.org/10.1016/j.pain.2007.08.013

18. Torrance N, Smith BH, Bennett MI, Lee AJ. The epidemiology of chronic pain of predominantly neuropathic origin: results from a general population survey. J Pain. 2006;7(4):281-9. http://dx.doi.org/

19. Merskey H, Bogduk N, editors. Classification of chronic pain: description of chronic pain syndromes and definition of pain terms. Seattle: IASP Press; 1994.

20. Ministério da Saúde (BR), Instituto Nacional de Câncer. Cuidados paliativos oncológicos: controle da dor. Rio de Janeiro: Instituto Nacional de Câncer; 2001.

21. Atta N, Cruccu M, Haanpää A, Hansson P, Jensen TS, Nurmikko Tet al. EFNS guidelines on pharmacological treatment of neuropathic pain. Eur J Neurol. 2006;13(11):1153-69. http://dx.doi.org/10.1111/j.1468-1331.2006.01511.x 